\title{
Sensory characteristics of spoilage and volatile compounds associated with bacteria isolated from cooked and peeled tropical shrimps using SPME-GC-MS analysis
}

Emmanuel Jaffrès $^{\mathbf{a}, \mathbf{b}, \mathbf{c}, \mathbf{e}}$, Valérie Lalanne ${ }^{\mathbf{d}, \mathbf{e}}$, Sabrina Macé $^{\mathbf{a}, \mathbf{b}, \mathbf{c}, \mathbf{e}},{\text { Josiane } \text { Cornet }^{\mathbf{c}} \text {, Mireille Cardinal }}^{\mathbf{c}}$, Thierry Sérot ${ }^{\mathrm{d}, \mathrm{e}}$, Xavier Dousset ${ }^{\mathrm{a}, \mathrm{b}}$ and Jean-Jacques Joffraud ${ }^{\mathbf{c}, *}$

\author{
a LUNAM Université, Oniris, UMR 1014 Secalim, Nantes, F-44307, France \\ b INRA, Nantes, F-44307, France \\ ${ }^{c}$ Ifremer, Laboratoire Science et Technologie de la Biomasse Marine, BP 21105, 44311 Nantes Cedex 3, France \\ ' LUNAM Université, ONIRIS, UMR 6144 GEPEA, Flavor Unit, F 44307, France \\ ${ }^{e}$ CNRS, Nantes, F-44307, France
}

\author{
*: Corresponding author : Jean-Jacques Joffraud, Tel. : + 33240374284 ; fax : + 33240374071 , \\ email address : jean.jacques.joffraud@ifremer.fr
}

\begin{abstract}
:
The spoilage potential of six bacterial species isolated from cooked and peeled tropical shrimps (Brochothrix thermosphacta, Serratia liquefaciens-like, Carnobacterium maltaromaticum, Carnobacterium divergens, Carnobacterium alterfunditum-like and Vagococcus penaei sp. nov.) was evaluated. The bacteria were inoculated into shrimps, packaged in a modified atmosphere and stored for 27 days at $8{ }^{\circ} \mathrm{C}$. Twice a week, microbial growth, as well as chemical and sensory changes, were monitored during the storage period. The bacteria mainly involved in shrimp spoilage were $B$. thermosphacta, S. liquefaciens-like and C. maltaromaticum whose main characteristic odours were cheese-sour, cabbage-amine and cheese-sour-butter, respectively. The volatile fraction of the inoculated shrimp samples was analysed by solid-phase microextraction (SPME) and gas chromatography coupled to mass spectrometry (GC-MS). This method showed that the characteristic odours were most likely induced by the production of volatile compounds such as 3-methyl-1-butanal, 2,3-butanedione, 2-methyl-1-butanal, 2,3-heptanedione and trimethylamine.
\end{abstract}

\section{Research highlights}

Cooked shrimps are very sensitive to microbiological spoilage process. Spoilage bacteria can produce chemical compounds with off-flavour. Such compounds give rise to a shelf-life decrease of cooked shrimps. - Spoilage potential of bacteria evaluated using SPME-GC-MS and sensory analysis. B. thermosphacta, S. liquefaciens, C. maltaromaticum are the main spoilage bacteria.

Keywords : Shrimp; Bacteria; Spoilage; Sensory analysis; Volatile compounds; SPME/GC-MS 


\section{Introduction}

Shrimps are of economic importance worldwide, particularly in Europe which is the world's main importer of shrimp (FAO-Globefish/Josupeit, 2008). The majority of shrimps purchased by French consumers are cooked and chilled (OFIMER, 2006). However, this foodstuff is considered very sensitive to microbial spoilage. Indeed, after heat treatment in the preparation process, shrimps can undergo bacterial recontamination from the processing equipment and the environment in the production plant (Bagge-Ravn et al. 2003; Huss et al. 2000). These bacteria can grow very quickly on the shrimp matrix due to the ideal conditions of a neutral $\mathrm{pH}$, a high water activity (Aw) and a high content of low molecular weight compounds such as free amino-acids and nucleotides (Gram and Huss, 1996). A few of them, named specific spoilage organisms (SSO), can present a metabolism resulting in the formation of amines (trimethylamine), sulphides, alcohols, ketones, aldehydes and organic acids (Gram and Dalgaard, 2002; Gram et al. 2002). These chemical compounds give rise to the unpleasant and unacceptable off-flavors/odors associated with the sensory spoilage phenomenon and progressively result in a decrease in shelf-life. In a previous study, Jaffrès et al. (2009) highlighted the main bacterial genera and species related to the spoilage microbiota of cooked and peeled tropical shrimps, packaged in a modified atmosphere (MAP). Lactic acid bacteria, mainly represented by the genera Carnobacterium, Vagococcus and Enterococcus, were found to dominate the microbiota of the studied shrimps, followed by Brochothrix thermosphacta and Serratia liquefaciens. Several of these bacteria were already known to be involved in the production of off-odors, characteristic of spoiled seafood products. Indeed, Serratia liquefaciens was found to be one of the most spoiling microorganisms in cold-smoked salmon (Joffraud et al. 2006; Stohr et al. 2001), producing trimethylamine (related to urine), dimethylsulphide and thiobarbituric acid (sulphur odors related to garlic, cabbage or mud). $B$. thermosphacta was also found to be responsible for the production of the volatile compounds, 2-hexanone and 2-heptanone, which were shown to be related to the formation of sour, blue-cheese and pungent off-odors in cold-smoked salmon (Joffraud et al. 2001). In chilled and MAP cooked peeled Nordic shrimps, B. thermosphacta was also shown to produce 2,3-butanedione (diacetyl), 3-methyl-1-butanal, and 3-methyl-1-butanol (Laursen et al. 2006; Mejlholm et al. 2005). These compounds seemed to be responsible for the formation of strong butter, buttermilk-like, sour and nauseous off-odors. For Carnobacterium species, however, their spoilage potential has not been clearly established in seafood products. Several previous studies on the spoilage of cold-smoked salmon showed that the inoculation of $C$. divergens and C. maltaromaticum produced either no off-odors or a very weak butter-like odor, possibly resulting from the formation of 2,3-butanedione and 2,3-pentanedione, which was not considered as a spoilage off-odor by a trained panel (Joffraud et al. 2001; Leroi et al. 1998; Stohr et al. 2001). Furthermore, Laursen et al. (2006) showed that the spoilage potential of Carnobacterium species were species- and strain-dependent in chilled and MAP cooked peeled Nordic shrimps. Some strains of $C$. divergens and C. maltaromaticum were able to cause off-odors, such as chlorine, chemical, malty, nutty, sour and nauseous, probably generated by the production of ammonia, various alcohols, aldehydes, and ketones. Conversely, other strains of $C$. maltaromaticum were unable to produce these spoilage compounds and were not involved in shrimp spoilage. Mejlholm et al. (2005) found that $C$. maltaromaticum and $B$. thermosphacta in co-culture on chilled and MAP cooked peeled Nordic shrimps produced a particular wet-dog off-odour, which was not identified when the two species were studied separately. This combined activity of these two species was confirmed by Laursen et al. (2006), who showed that the wet-dog off-odour did not result from the production of a new metabolite by the co-culture, but rather from the interaction between metabolites formed by the two species. All of these previous works show that the spoilage potential of SSO depends on the nature of the food matrix from which they have been isolated. The identification of the bacteria responsible for spoilage in cooked shrimp is important to allow a better understanding of the mechanisms involved in spoilage, and of any changes in the 
product after heat treatment. To our knowledge, only the spoilage characteristics of bacteria isolated from cooked Nordic shrimps have been studied to date.

The purpose of this present study was to investigate the spoilage potential of several bacteria, belonging to different taxonomic groups, previously isolated from tropical cooked shrimps (Jaffrès et al. 2010; Jaffrès et al. 2009). The spoilage potential of these bacteria was assessed by monitoring their sensory profile. The volatile fraction released by bacteria from spoiled, cooked tropical shrimps was analysed by solid-phase microextraction (SPME) and gas chromatography coupled to mass spectrometry (GC-MS). SPME is a single-step solventfree extraction technique for volatile compound extraction, with a high sensitivity (Arthur and Pawliszyn, 1990). To date, SPME has been used for the analysis of volatile compounds in different foodstuffs (Duflos et al. 2006; Risticevic et al. 2009) and various biological and inorganic materials (Nicolle et al. 2008; Pragst, 2007).

\section{Materials and methods}

\subsection{Bacterial strains}

All strains tested in this study, selected from the laboratory collection, had previously been isolated from cooked and peeled tropical shrimps in MAP (Jaffrès et al. 2010; Jaffrès et al. 2009) and were maintained as frozen stocks at $-80^{\circ} \mathrm{C}$ in a cryoprotector medium containing glycerol (10 \%). These strains belonged to the taxonomic groups: Brochothrix thermosphacta, Carnobacterium maltaromaticum, Carnobacterium divergens, Carnobacterium alterfunditum-like, Serratia liquefaciens and Vagococcus penaei sp nov. Each group was represented by five strains (Table 1).

\subsection{Strain culture, sample inoculation and packaging}

Tropical shrimp samples (Penaeus vannamei) used in this study were prepared in semiindustrial conditions in the experimental pilot food processing unit of the Higher Institute of Food Science and Technology (ENITIAA-ONIRIS) Nantes, France. The shrimps (size 112/132, 112 to 132 shrimps per kg) were farmed, caught, peeled and frozen in Colombia and supplied in the frozen state to the pilot unit, and kept at $-20^{\circ} \mathrm{C}$ until the start of the experiments. Shrimps were cooked in a boiling, salted water bath $\left(30 \mathrm{~g} \mathrm{NaCl}^{-1}\right)$ until a core temperature of around $+80^{\circ} \mathrm{C}$ was achieved. Shrimps were then drained and rapidly cooled by storage in a cooling room $\left(-20^{\circ} \mathrm{C}\right)$ until a core temperature of around $+2^{\circ} \mathrm{C}$ was reached. The cooked shrimp samples were kept at $+2^{\circ} \mathrm{C}$ in a chilled room until the inoculation process. Strains were pre-cultured individually in brain heart infusion broth (BHI) (Difco Laboratories, Detroit, MI, USA) then cultured in the same conditions until an absorbance-estimated concentration level of approximately $10^{8} \mathrm{cells} \mathrm{ml}^{-1}$ was achieved. The cultures of five strains belonging to the same species were pooled in a sterile vial and mixed. The mixture was thousand-fold diluted in sterile peptone water $(0.85 \% \mathrm{NaCl}$ and $0.1 \%$ peptone), in order to achieve a diluted inoculation mixture. The inoculation and packaging processes were carried out in a white-room of the experimental pilot unit. Each diluted inoculation mixture was sprayed on a batch of approximately $4.5 \mathrm{~kg}$ of cooked and peeled shrimps (around $20 \mathrm{ml}$ of diluted mixture/kg corresponding to a fifty-fold dilution) under a laminar flow hood, by spraying both sides with an airbrush coupled with a compressor and equipped with a sterile needle (Dalbe, Nantes, France). A control was prepared by spraying sterile peptone water instead of the strain mixture onto cooked and peeled shrimps. Each batch of inoculated shrimps and the shrimp control was divided and placed into several plastic packets (around $190 \mathrm{~g}$ portions) and packaged in a modified atmosphere $\left(50 \% \mathrm{CO}_{2}\right.$ and $\left.50 \% \mathrm{~N}_{2}\right)$ using a Multivac T 200 machine (Hagenmüller, Wolfertschwenden, Germany) and a low gas 
permeability film like LDPE (low density polyethylene). All batches of inoculated shrimps and the control were stored at $8^{\circ} \mathrm{C}$ for several weeks and, twice a week, two series of analyses were carried out including sensory, chemical and microbiological analyses, until sensory rejection was reached. The volatile compounds produced by inoculated bacteria were then detected and analysed by solid-phase microextraction (SPME) and gas chromatography coupled to a mass spectrometry system (GC-MS). Each analysis was also carried out in the same conditions for the shrimp control.

\subsection{Enumeration of inoculated strains}

A 30-g portion of shrimp samples was aseptically weighed into $120 \mathrm{ml}$ of sterile physiological saline solution $(0.85 \% \mathrm{NaCl})$ with $0.1 \%$ peptone in a sterile plastic bag and blended with a stomacher 400 (Seward Medical, London, UK) for $2 \mathrm{~min}$. The homogenised analysis solution was kept at room temperature for 30 min for bacterial resuscitation. Several appropriate 10fold dilutions of the analysis solution were carried out in sterile physiological saline solution and $0.1 \mathrm{ml}$ of each was spread on a plate. The following media were used to enumerate the inoculated strains (Joffraud et al. 2006): plate count agar (PCA; Biokar) incubated aerobically for $3-5$ days at $25^{\circ} \mathrm{C}$ for $B$. thermosphacta and S. liquefaciens, and Elliker broth (Biokar) with $1.5 \%$ agar, placed in anaerobic jars with Anaerocult $A$ (Merck) at $20^{\circ} \mathrm{C}$ for 5 days for $C$. maltaromaticum, Carnobacterium divergens, Carnobacterium alterfunditum-like and Vagococcus penaei sp. nov. The possible background microflora was evaluated by means of enumerations performed on the shrimp control using PCA.

\subsection{Chemical analysis}

The flesh remaining in the bags opened for microbiological analysis was homogenised in a Waring Blender (New Hartford, CO, USA). Total Volatile Basic Nitrogen (TVBN) and Trimethylamine (TMA) were measured in duplicate by the Conway microdiffusion method (Conway and Byrne, 1933). The $\mathrm{pH}$ value was measured in the five-fold-diluted flesh with a pH meter (Mettler Delta, AES, Combourg, France).

\subsection{Sensory analysis}

Eleven trained panellists, experienced in seafood sensory evaluation, carried out the sensory analysis of shrimp samples, according to a conventional profile (ISO 13299, 2003). For shrimp odor evaluation, the list of descriptors established according to the procedure described by Matamoros et al. (2009) was tested in preliminary sessions, where fresh cooked and peeled tropical shrimps, stored at $+4^{\circ} \mathrm{C}$, were evaluated each week for six weeks. These sessions enabled only eight relevant descriptors to be selected (Table 2).

Sensory sessions were performed in individual testing booths (ISO 8589, 1989) equipped with a computerised system using Fizz $2.30 \mathrm{C}$ software (Biosystèmes, Couternon, France). Panellists were required to score each descriptor on an unstructured scale anchored by the terms low intensity (0) and high intensity (10). They received seven samples (4 shrimps per sample), six inoculated and one control. Products were assigned 3 digit numbers, randomised and served simultaneously to the panellists, after 1 hour in an oven at $18^{\circ} \mathrm{C}$. At the end of the evaluation, panellists identified the level of spoilage of each sample: NS, nonspoiled; LS, lightly spoiled; MS, moderately spoiled and SS, strongly spoiled. The frequencies obtained for each class by all the panellists were recorded for each bacterial group, on each analysis day. The products were considered to be in the spoilage phase when at least $50 \%$ of the assessors classified them at the SS level.

Summary statistics (mean, standard deviation, minimum, maximum), analysis of variance and Duncan's multiple range test were performed using Statgraphics Plus Centurion XV.I 
software (Sigma Plus, Paris, France). The significant statistical level was set at $p<0.05$. Principal component analysis (PCA) with standardisation was performed on the means of the scores for each sensory descriptor. For levels of spoilage (NS, LS, MS, SS), frequencies were treated by a correspondence factorial analysis (CFA). Multivariate data processing was performed with Uniwin Plus 6.1 software (Sigma Plus).

\subsection{Analysis of volatile compounds}

Volatile compounds produced by inoculated bacteria were analysed using a gas chromatography device, model GC 7890A, Agilent (Agilent Technologies, Santa Clara, USA) coupled with a mass spectrometer $5975 \mathrm{C}$ VL (Agilent) and flame ionisation detector after solid-phase microextraction (SPME/GC-MS-FID). The extraction and injection processes were automatically performed using an autosampler MPS 2 (Gerstel, Mülheim, Germany). Briefly, a 4-g portion of shrimp sample was weighed into a $20 \mathrm{ml}$ vial with a polypropylene screw-on cap and a PTFE/silicone septum (Supelco, Bellefonte, PA, USA) to make it airtight. The vial was heated at $40^{\circ} \mathrm{C}$ for $50 \mathrm{~min}$ to equilibrate the system. The SPME fibre, $85 \mu \mathrm{m}$ carboxen/polydimethylsiloxane Stable Flex $^{\mathrm{TM}}$ (Supelco), was inserted through the septum and exposed in the headspace of the vial for $25 \mathrm{~min}$, to allow absorption of the volatile compounds onto the SPME fibre. The SPME fibre was then introduced into the injector port of the gas chromatograph for $5 \mathrm{~min}$ in splitless mode, set at $280^{\circ} \mathrm{C}$, in order to desorb the volatile compounds. The desorbed components were analysed on a capillary column Agilent $\mathrm{J} \& \mathrm{~W}$ DB- $5 \mathrm{~ms}$ (30 m length $\times 0.25 \mathrm{~mm}$ internal diameter $\times 0.5 \mu \mathrm{m}$ film thickness). Helium was used as carrier gas with a flow of $1.3 \mathrm{ml} / \mathrm{min}$ and the oven temperature was programmed as follows: $40^{\circ} \mathrm{C}$ for $5 \mathrm{~min}$, then ramped at $3^{\circ} \mathrm{C} \mathrm{min}^{-1}$ to $140^{\circ} \mathrm{C}$, then ramped at $6^{\circ} \mathrm{C} \mathrm{min}^{-1}$ to $280^{\circ} \mathrm{C}$, and held for $5 \mathrm{~min}$. Molecules of volatile compounds were detected by FID and mass selective detector. The detector operated in a mass range between 33 and 300 with a scan rate of $2 \mathrm{scans} / \mathrm{s}$. Compound identification was based on a comparison of retention indices (RI), mass spectra (comparison with standard MS spectra databases: WILEY 6, and with spectra of standards). Data were reported as log (peak area/g) for each compound detected.

\section{Results}

\subsection{Bacterial kinetics and pH}

The microbial growth of the six different bacterial groups, inoculated on cooked and peeled tropical shrimps, were monitored twice a week during the 27 days of the storage period under MAP at $8^{\circ} \mathrm{C}$. Figs. $1 \mathrm{~A}$ and $\mathrm{B}$ show the growth pattern of these six different bacterial groups. Most of the cultures were inoculated in a range of $10^{4}-10^{5} \mathrm{cfu} \mathrm{\textrm {g } ^ { - 1 }}$, except for $C$. maltaromaticum and $V$. penaei, inoculated at $10^{3}-10^{4}$ cfu $\mathrm{g}^{-1}$. The control was under the enumeration threshold $\left(50 \mathrm{cfu} \mathrm{g}^{-1}\right)$ until 20 days of storage then an increase in growth was detected with around $10^{6} \mathrm{cfu} \mathrm{g}^{-1}$ at the end of storage. All bacterial groups grew well on the cooked shrimp matrix, reaching their maximum levels after 1-2 weeks of storage with final counts ranging from $10^{8}$ to $10^{9} \mathrm{cfu} \mathrm{g}^{-1}$. Depending on the inoculation levels, the growth curve patterns were different and two sets of bacterial groups could be distinguished. The first, including C. divergens, S. liquefaciens-like, C. alterfunditum-like and B. thermosphacta, increased rapidly during the first week and reached their maximum of growth after six days of storage. This growth process led to a decrease in $\mathrm{pH}$ from 6.7 to 5.8-5.9 for $B$. thermosphacta and $C$. alterfunditum-like when the $\mathrm{pH}$ value was quite stable at 6.7-6.4 for $C$. divergens and $S$. liquefaciens-like during the storage. The growth of the second set, including $C$. maltaromaticum and $V$. penaei which were inoculated at a lower level, was 
delayed and their maximum was not reached until 12 days of storage leading to a drop in $\mathrm{pH}$ from 6.7 to 6.1 .

\subsection{Chemical changes}

Most of the bacterial groups produced a significant amount of TVBN compared to the control, which did not exceed $20 \mathrm{mg}-\mathrm{N} 100 \mathrm{~g}^{-1}$ (Figs. 2A, B). The highest producers were $C$. divergens, $C$. maltaromaticum and $V$. penaei, which reached a maximum production rate of TVBN ranging from 80 to $90 \mathrm{mg}-\mathrm{N} 100 \mathrm{~g}^{-1}$. However, $C$. divergens exhibited a better yield than both the others, because it reached the maximum of production at nine days of storage corresponding to the end of the exponential growth phase whereas, in the same period, the TVBN production of $C$. maltaromaticum and $V$. penaei did not exceed $15 \mathrm{mg}-\mathrm{N} 100 \mathrm{~g}^{-1}$. Moreover, these species reached their maximum of production after 20 days of storage, approximately one week later than their maximum growth level. The three other bacterial groups exhibited a lower and more gradual production of TVBN during storage, reaching 72 , 60 and $42 \mathrm{mg}-\mathrm{N} 100 \mathrm{~g}^{-1}$ at the end of storage for $C$. alterfunditum-like, B. thermosphacta and S. liquefaciens-like, respectively. TMA production (data not shown) was very low for all bacterial groups or even non-existent during all the storage period for $C$. alterfunditum-like, C. maltaromaticum and $V$. penaei as well as for the control. Among the bacterial groups which exhibited a very low TMA production, only S. liquefaciens-like showed an increase in the amount of TMA during storage, but this did not exceed $10 \mathrm{mg}-\mathrm{N} 100 \mathrm{~g}^{-1}$.

\subsection{Sensory characteristics of inoculated shrimps}

Correspondence factorial analysis (CFA) performed on the frequencies of the four levels of spoilage indicated the spoilage potential of each bacterial group (Fig. 3). The first two principal components enabled around $90 \%$ of the total information to be restored. The first axis, which restored $63 \%$ of the total information, separated the strongly-spoiled samples (right part of Fig. 3) from the non-spoiled samples (left part of Fig. 3). The second axis (28\% of the total information) discriminated non-spoiled and strongly spoiled (upper part) from lightly spoiled and moderately spoiled (lower part), respectively. Control samples after 20 days of storage were located in the area of non-spoiled samples. Several sensory evolution patterns were observed according to the strains. Indeed, only three bacterial groups were located in the strongly-spoiled area: $B$. thermosphacta, S. liquefaciens-like and $C$. maltaromaticum. They were considered as the most spoiling micro-organisms with different evolutions in their spoilage activity. B. thermosphacta reached the strongly spoiled level at day 9 of storage (63\% of the panellists), followed by S. liquefaciens-like at day 13 (around $50 \%$ of the panellists and confirmed at day 27 by $90 \%$ ) and C. maltaromaticum at day 16 ( $50 \%$ of the panellists and confirmed at day 27 by $75 \%$ ). Other bacterial groups were mainly classified at the non- and lightly spoiled level ( $V$. penaei and $C$. alterfunditum-like) or moderately spoiled level (C. divergens), until the end of the storage period and were considered as non-spoiling or very weakly spoiling micro-organisms.

The Principal Component Analysis (PCA) (Fig. 4) performed on the mean scores of profiling tests presents the main odor characteristics for each sample. This figure shows the simultaneous projection of samples and sensory descriptors on the first 1-2 plane. The first axis (56\% of the information) is mainly characterised by descriptors such as rice/crustacean on one side, and sour/fermented, cheese/feet, overall intensity of odor, amine/urine, cabbage/gas/garlic and floor cloth on the other side. This component can be considered as an axis of spoilage, as it divides the typical odors of freshly processed, brined and cooked shrimps on the left side from the spoiling off-odors on the right side. Milky-boiled odors on the upper part of the graph mainly defined the second component (25\% of the information). The characteristic odor of the non-spoiled control at day 2 was rice/crustacean. After 27 days, the 
control had the same odor. The samples inoculated with $B$. thermosphacta and $S$. liquefaciens-like strains kept the rice/crustacean non-spoiled odor until day 2 . Then, $B$. thermosphacta exhibited mainly cheese/feet and sour/fermented off-odors from day 9 until the end of storage, with a tinge of milky-boiled odor at day 27 , while for S. liquefaciens-like, cabbage/gas/garlic, amine/urine and floor cloth off-odors were noted from day 6 until the end of storage. At day 9 , samples inoculated with C. maltaromaticum strains were similar to the control with a rice/crustacean non-spoiled odor. From day 13 until the end, they exhibited the same odor characteristics as B. thermosphacta (cheese/feet, sour/fermented and milkyboiled off-odors) but these were less pronounced. Interestingly for these samples, a sensory descriptor of butter odor, which was not presented in the selected list, was systematically suggested by panellists until the end of storage. From day 6 , samples with $C$. divergens strains exhibited milky-boiled off-odors and then, from day 13 until the end, they revealed sour/fermented and cheese/feet off-odors but less pronounced than for C. maltaromaticum and $B$. thermosphacta. The other inoculated shrimp samples, with $V$. penaei and $C$. alterfunditum-like strains, kept the rice/crustacean non-spoiled odor until the end of storage. Nevertheless, samples with $V$. penaei strains exhibited the same butter odor at days 13 and 16 as $C$. maltaromaticum. All the odors characteristic of the bacterial groups are summarised in Table 3.

\subsection{Volatile compounds}

Only bacterial groups which were considered as the most spoiling micro-organisms (i.e. Brochothrix thermosphacta, Serratia liquefaciens-like and Carnobacterium maltaromaticum), were included in the volatile compound research by SPME/GC-MS-FID analysis. Approximately fifty compounds were identified in the samples spoiled by each bacterial group and in the control sample. However, only the thirty most abundant compounds were considered (Table 4). In the samples spoiled by the Brochothrix thermosphacta group the most significant compounds detected were 3-methyl-1-butanal, 2,3-butanedione, 2-methyl-1butanal, 2-methyl-1-butanol, acetaldehyde, 2-methyl-1-propanal and ethyl acetate. But 2methyl-1-propanol, 2-hexanol and 2,3-heptanedione were also detected. When samples were spoiled by Serratia liquefaciens-like strains, 2,3-butanedione, ethyl acetate, 1-propanol and acetaldehyde were detected. This group also produced trimethylamine and 2-butanol which were not produced by other groups. Alteration by Carnobacterium maltaromaticum strains led to production of 3-methyl-1-butanal, 2-methyl-1-butanal, 2-methyl-1-butanol, ethyl acetate, 2-methyl-1-propanal, 2,3-butanedione and acetaldehyde. It also produced 3-methyl2-butanone, 3-methyl-1-butene, thiocarbamide and cyclopentanol which were not produced by other groups.

\section{Discussion}

The objective of this study was to investigate the spoilage potential of six bacterial species on cooked and peeled tropical shrimps. All species tested were previously isolated from the spoilage microbiota of cooked and peeled tropical shrimps during an earlier study (Jaffrès et al. 2010; Jaffrès et al. 2009). However, the individual ability of each species to produce sensory changes on this type of product had to be tested, in order to determine which are really involved in the production of volatile compounds and undesirable odor characteristics of the spoilage process. In this work, we chose to inoculate each bacterial species using a mix of five strains in order to avoid the strain effect, previously described by Stohr et al. (2001) and Joffraud et al. (2006), where strains belonging to the same species can present a heterogeneous spoilage potential when individually tested. Consequently, the sensory changes observed in this study, and assigned to each bacterial group, resulted from the combination of five mixed strains. Interestingly in the present study, the $C$. divergens group 
were considered as very weakly spoiling micro-organisms with a low development of milkyboiled, sour/fermented and cheese/feet off-odors, while the same Carnobacterium species, when inoculated on a related seafood product (i.e. chilled and MAP cooked peeled Nordic shrimps), was able to develop off-odors of strongest intensity such as chlorine, chemical, malty, nutty, sour and nauseous, probably generated by the production of ammonia, various alcohols, aldehydes, and ketones (Laursen et al. 2006). This contrast in the spoilage behavior for $C$. divergens, confirms the previous conclusion (Laursen et al. 2006) that the spoilage potential of Carnobacterium species was species-, strain- but also food matrixdependent.

For B. thermosphacta, S. liquefaciens-like and C. maltaromaticum, the strongest spoiling bacteria in this work, the inoculated shrimps were rejected by the panel just after the exponential stage and at the beginning of the stationary phase of the growth curves (i.e. days 9,13 and 16, respectively). This behaviour is typical of the SSOs described by (Gram and Dalgaard, 2002). In fact, sensory rejection occurs after the amount of chemical metabolites, produced by bacteria, have reached a certain level following an exponential evolution (Gram and Huss, 1996). Regarding the chemical results, we observed that there was no correlation between the quantity of TVBN and sensory rejection. Indeed, levels of TVBN produced by $C$. divergens, $C$. alterfunditum-like and $V$. penaei, which were considered as non- or very weakly spoiling bacteria, were higher than those produced by the strongest spoiling bacteria, except for $C$. maltaromaticum. This result confirms that TVBN is probably not a good indicator of the sensory spoilage of cooked peeled shrimps, as was concluded by Joffraud et al. (2006) for cold-smoked salmon. Concerning TMA production, the only bacterial group which exhibited a slight production was $\mathrm{S}$. liquefaciens-like with approximately $8 \mathrm{mg}-\mathrm{N} 100 \mathrm{~g}^{-}$ ${ }^{1}$. This was then confirmed by the SPME/GC-MS-FID analysis where trimethylamine was detected only in the headspace of shrimps inoculated with this species.

Our results show that the spoilage potential of $B$. thermosphacta strains was revealed by their ability to produce cheese/feet and sour/fermented odors, most likely induced by volatile compounds. Indeed, several volatile compounds detected in shrimp spoiled by this bacterial group have already been described as being responsible for characteristic flavors, such as 2,3-heptanedione for butter and cheesy odors (Fenaroli, 2001), 3-methyl-1-butanal for malty and coffee odors (Varlet et al. 2006), 2,3-butanedione for buttery odors (Prost et al. 2004; Senger-Emonnot et al. 2006) and 2-methyl-1-butanal for strong burnt odors (Fukami et al. 2002). These results are in accordance with those of Laursen et al. (2006), who showed that $B$. thermosphacta, when inoculated on cooked and peeled Nordic shrimps, produced notably 2,3-butanedione and 3-methyl-1-butanal, which led to the formation of strong butter, buttermilk-like, sour and nauseous off-odors. Strains of $S$. liquefaciens-like displayed a spoilage potential by producing cabbage/gas/garlic, amine/urine and floor cloth off-odors. This sensory profile could be related to the presence of some volatile compounds produced by this bacterial group, including trimethylamine already known to be responsible for strong fishy and ammonia-like off-odors (Gram and Dalgaard, 2002; Jørgensen et al. 2001), and ethyl acetate and 2-butanol, already associated with solvent/pungent and glue-like odors, respectively (Jørgensen et al. 2001). C. maltaromaticum strains exhibited a spoilage potential with the production of cheese/feet, sour/fermented and butter flavors and they released the volatile compounds 3-methyl-1-butanal, 2-methyl-1-butanal, 2,3-butanedione and ethyl acetate. However, they did not produce 2,3-heptanedione which has been related to the butter/cheesy odor (Fenaroli, 2001). This finding illustrates the fact that a characteristic odor is not necessarily related to one specific chemical metabolite, but can result from the combination of several compounds (Jørgensen et al. 2001; Olafsdottir et al. 2000). C. maltaromaticum has already been described as producing a butter-like odor on cold-smoked salmon, probably due to the release of 2,3 butanedione and 2,3 pentanedione (Joffraud et al. 2001). 
These species do not exhibit their spoilage potential only in seafood products. Several previous approaches similar to this work have highlighted the release of different volatile compounds by bacteria that contribute to the overall decrease in quality, notably in meat products. Indeed, the psychrotrophic species $B$. thermosphacta represents one of the major constituents of the spoilage microflora of meat stored aerobically and is occasionally recognised as the dominant organism. For this species, meat is an ecological niche where it can grow under both aerobic and anaerobic conditions and produce undesirable odors, such as cheesy associated with acetoin/diacetyl and 3-methylbutanol production (Dainty and Mackey, 1992; Pin et al. 2002). Ercolini et al. (2009) have also shown that $C$. maltaromaticum, when inoculated on meat under vacuum-packed storage at $7^{\circ} \mathrm{C}$, could produce compounds such as 2-ethyl-1-hexanol, 2-buten-1-ol, 2-hexyl-1- octanol, 2nonanone, and 2-ethylhexanal as well as the highest number of aldehydes, lactones, and sulphur compounds. In the same previous study, Serratia proteamaculans, also called Serratia liquefaciens-like (Grimont et al. 1982) as in the present work, was the highest producer of some alcohols (such as 1-octen-3-ol) and some esters (such as isoamyl acetate).

In conclusion, this study has contributed to improving our knowledge concerning the spoilage mechanisms in cooked shrimps. It shows that three bacterial species are mainly responsible for shrimp sample spoilage (i.e. Brochothrix thermosphacta, Serratia liquefaciens-like and Carnobacterium maltaromaticum) notably by the production of several volatile compounds known to originate from different catabolic pathways, such as amino acid metabolism for 3methyl-1-butanal or 2-methyl-1-butanal, glycogen metabolism for 2,3-butanedione or 2,3heptanedione, sugar fermentation for ethyl acetate and also anaerobic respiration by certain bacteria which can induce TMAO reduction to trimethylamine. These compounds can generate individually or in combination, off-odors and flavors characteristic of the spoilage process. This study was performed by testing each species group independently of the others. Further investigations will be needed to determine the incidence of the combination between species, which could change the growth resulting in e.g. Jameson effect (Ross, 2008), the overall metabolism, and associations of volatile compounds, which could modify the perception of odors as previously shown by Laursen et al. (2006).

The sensory patterns with the four levels of spoilage of the shrimp shown in figures 3 and 4 are more or less analogous to the quality grading into four phases for both fresh and cooked fish as previously described (Burgess et al. 1965 ; Connell, 1975). In this respect, the sensory methodology developed in this study could be used by the plants performing the cooking process from frozen raw shrimps coming from Asia or South America to assess the quality of their product and to fix a sensible duration for the shelf-life.

Our results show that the analysis of volatile compounds is a relevant approach to identify and characterize the alteration of the shrimp meat linked to the presence of bacteria. However, the absence of truly specific markers of a species prevents, currently, the routine use of this technique for characterizing the state of freshness of raw material in an industrial plant. Further work will be required to use the analysis of volatile compounds as an index of quality for example through a metabolomic-like approach.

In the present work, the determination of active spoilers among the spoilage microbiota will be useful in further studies to investigate different growth parameters and to design models as described by McMeekin et al. (1993), for predicting deterioration in the quality of cooked shrimps. 


\section{Acknowledgements}

This study was carried out as part of the IMIBIOMER program, supported by Valorial, managed by Pôle Agronomique Ouest (PAO) and financially supported by the regions of Bretagne and Pays de La Loire. We are grateful to Fabrice Frassetto, technical manager of the ONIRIS technological hall, for welcoming us and for allowing access to the experimental pilot unit. We thank STBM laboratory members: Sarah Le Glaunec and Frédérique Gigout for the microbiological and chemical analyses. Emmanuel Jaffrès received a Ph.D. Grant awarded by Ifremer and ENITIAA-ONIRIS.

\section{References}

Arthur, C.L., Pawliszyn, J., 1990. Solid phase microextraction with thermal desorption using fused silica optical fibers. Analytical Chemistry 62, 2145-2148.

Bagge-Ravn, D., Ng, Y., Hjelm, M., Christiansen, J.N., Johansen, C., Gram, L., 2003. The microbial ecology of processing equipment in different fish industries-analysis of the microflora during processing and following cleaning and disinfection. International Journal of Food Microbiology 87, 239-250.

Burgess, G.H.O., Cutting, C.L., Lovern, J.A., Waterman, J.J., 1965. Fish spoilage. In: Burgess, G.H.O. [et al] (Eds.), Fish Handling and Processing. Her Majesty's Stationery Office, Edinburgh, Scotland, pp. 346-356.

Connell, J.J., 1975. Methods of Assessing and Selecting Quality. In: Torry Research Station. (Ed.), Control of Fish Quality. Fishing News Books Ltd, Surrey, England, pp. 107-132.

Conway, E.J., Byrne, A., 1933. An absorption apparatus for the micro-determination of certain volatile substances: The micro-determination of ammonia. Biochemical Journal 27, 419-429.

Dainty, R.H., Mackey, B.M., 1992. The relationship between the phenotypic properties of bacteria from chill-stored meat and spoilage processes. Society for Applied Bacteriology Symposium Series 73, 103S-114S.

Duflos, G., Coin, V.M., Cornu, M., Antinelli, J.F., Malle, P., 2006. Determination of volatile compounds to characterize fish spoilage using headspace/mass spectrometry and solidphase microextraction/gas chromatography/mass spectrometry. Journal of the Science of Food and Agriculture 86, 600-611.

Ercolini, D., Russo, F., Nasi, A., Ferranti, P., Villani, F., 2009. Mesophilic and psychrotrophic bacteria from meat and their spoilage potential in vitro and in beef. Applied and Environmental Microbiology 75, 1990-2001.

FAO-Globefish/Josupeit, H. 2008. Global Technical and Trade Conference on Shrimp : US and EU Market, Rome, Italy. www.globefish.org.

Fenaroli, G. 2001. Fenaroli's Handbook of Flavor Ingredients 4th Edition. Burdock, G. A. ed. CRC Press, Orlando, Florida, USA.

Fukami, K., Ishiyama, S., Yaguramaki, H., Masuzawa, T., Nabeta, Y., Endo, K., Shimoda, M., 2002. Identification of distinctive volatile compounds in fish sauce. Journal of Agricultural and Food Chemistry 50, 5412-5416. 
Gram, L., Dalgaard, P., 2002. Fish spoilage bacteria-problems and solutions. Current Opinion in Biotechnology 13, 262-266.

Gram, L., Huss, H.H., 1996. Microbiological spoilage of fish and fish products. International Journal of Food Microbiology 33, 121-137.

Gram, L., Ravn, L., Rasch, M., Bruhn, J.B., Christensen, A.B., Givskov, M., 2002. Food spoilage-interactions between food spoilage bacteria. International Journal of Food Microbiology 78, 79-97.

Grimont, P.A.D., Grimont, F., Irino, K., 1982. Biochemical characterization of Serratia liquefaciens sensu stricto, Serratia proteamaculans, and Serratia grimesii sp. nov. Current Microbiology 7, 69-74.

Huss, H.H., Reilly, A., Karim Ben Embarek, P., 2000. Prevention and control of hazards in seafood. Food Control 11, 149-156.

ISO, International Organization for Standardization, 1989. Sensory analysis - General guidance for the design of test rooms, ISO 8589, Geneva, Switzerland.

ISO, International Organization for Standardization, 2003. Sensory analysis - Methodology General guidance for establishing a sensory profile, ISO 13299, Geneva, Switzerland.

Jaffrès, E., Prevost, H., Rossero, A., Joffraud, J.J., Dousset, X., 2010. Vagococcus penaei sp. nov., isolated from spoilage microbiota of cooked shrimp (Penaeus vannamei). International Journal of Systematic and Evolutionary Microbiology 60, 2159-2164.

Jaffrès, E., Sohier, D., Leroi, F., Pilet, M.F., Prevost, H., Joffraud, J.J., Dousset, X., 2009. Study of the bacterial ecosystem in tropical cooked and peeled shrimps using a polyphasic approach. International Journal of Food Microbiology 131, 20-29.

Joffraud, J.J., Cardinal, M., Cornet, J., Chasles, J.S., Leon, S., Gigout, F., Leroi, F., 2006. Effect of bacterial interactions on the spoilage of cold-smoked salmon. International Journal of Food Microbiology 112, 51-61.

Joffraud, J.J., Leroi, F., Roy, C., Berdague, J.L., 2001. Characterisation of volatile compounds produced by bacteria isolated from the spoilage flora of cold-smoked salmon. International Journal of Food Microbiology 66, 175-184.

Jørgensen, L.V., Huss, H.H., Dalgaard, P., 2001. Significance of volatile compounds produced by spoilage bacteria in vacuum-packed cold-smoked salmon (Salmo salar) analyzed by GC-MS and multivariate regression. Journal of Agricultural Food Chemistry 49, 2376-2381.

Laursen, B.G., Leisner, J.J., Dalgaard, P., 2006. Carnobacterium species: effect of metabolic activity and interaction with Brochothrix thermosphacta on sensory characteristics of modified atmosphere packed shrimp. Journal of Agricultural and Food Chemistry 54, 3604-3611.

Leroi, F., Joffraud, J.J., Chevalier, F., Cardinal, M., 1998. Study of the microbial ecology of cold-smoked salmon during storage at $8^{\circ} \mathrm{C}$. International Journal of Food Microbiology 39, 111-121.

McMeekin, T.A., Olley, J., Ross, T., Ratkowsky, D.A., 1993. Predictive Microbiology: Theory and Application. Research Studies Press Ltd, Taunton, England. 
Matamoros, S., Leroi, F., Cardinal, M., Gigout, F., Kasbi Chadli, F., Cornet, J., Prévost, H., Pilet, M.F., 2009. Psychrotrophic lactic acid bacteria used to improve the safety of vacuumpackaged cooked and peeled tropical shrimp and cold-smoked salmon. Journal of Food Protection 72, 365-374.

Mejlholm, O., Boknaes, N., Dalgaard, P., 2005. Shelf life and safety aspects of chilled cooked and peeled shrimps (Pandalus borealis) in modified atmosphere packaging. Journal of Applied Microbiology 99, 66-76.

Nicolle, J., Desauziers, V., Mocho, P., 2008. Solid phase microextraction sampling for a rapid and simple on-site evaluation of volatile organic compounds emitted from building materials. Journal of Chromatography A 1208, 10-15.

OFIMER. 2006. Bilan annuel 2006 : Consommation des produits de la pêche et de l'aquaculture. www.ofimer.fr.

Olafsdottir, G., Hognadottir, A., Martinsdottir, E., Jonsdottir, H., 2000. Application of an electronic nose to predict total volatile bases in capelin (Mallotus villosus) for fishmeal production. Journal of agricultural and food chemistry 48, 2353-2359.

Pin, C., Garcia de Fernando, G.D., Ordonez, J.A., 2002. Effect of modified atmosphere composition on the metabolism of glucose by Brochothrix thermosphacta. Applied and Environmental Microbiology 68, 4441-4447.

Pragst, F., 2007. Application of solid-phase microextraction in analytical toxicology. Analytical and Bioanalytical Chemistry 388, 1393-1414.

Prost, C., Hallier, A., Cardinal, M., Serot, T., Courcoux, P., 2004. Effect of Storage Time on Raw Sardine (Sardina pilchardus) Flavor and Aroma Quality. Journal of Food Science 69, 198-204.

Risticevic, S., Niri, V.H., Vuckovic, D., Pawliszyn, J., 2009. Recent developments in solidphase microextraction. Analytical and Bioanalytical Chemistry 393, 781-795.

Ross, T., 2008. Microbial Ecology in Food Safety Risk Assessment. In: Schaffner, D.W. (Ed.), Microbial Risk Analysis of Foods. ASM Press, Washington DC, USA, pp. 89-93.

Senger-Emonnot, P., Rochard, S., Pellegrin, F., George, G., Fernandez, X., LizzaniCuvelierb, L., 2006. Odour active aroma compounds of sea fig (Microcosmus sulcatus). Food Chemistry 97, 465-471.

Stohr, V., Joffraud, J.J., Cardinal, M., Leroi, F., 2001. Spoilage potential and sensory profile associated with bacteria isolated from cold-smoked salmon. Food Research International 34, 797-806.

Varlet, V., Knockaert, C., Prost, C., Serot, T., 2006. Comparison of odor-active volatile compounds of fresh and smoked salmon. Journal of agricultural and food chemistry 54, 3391-3401. 
Fig. 1. Growth of bacterial groups on chilled and MAP cooked peeled tropical shrimps during storage at $8^{\circ} \mathrm{C} . \mathrm{A}:(\square)$ : Carnobacterium divergens, (): Carnobacterium alterfunditum-like, ( ): Serratia liquefaciens-like, ( $\mathbf{\square})$ : Brochothrix thermosphacta. B: ( $\boldsymbol{\Delta})$ : Carnobacterium maltaromaticum, ( ): Vagococcus penaei sp. nov., $(\diamond)$ : Control. The symbol " " indicates that counts were below the enumeration threshold (50 cfu g-1).
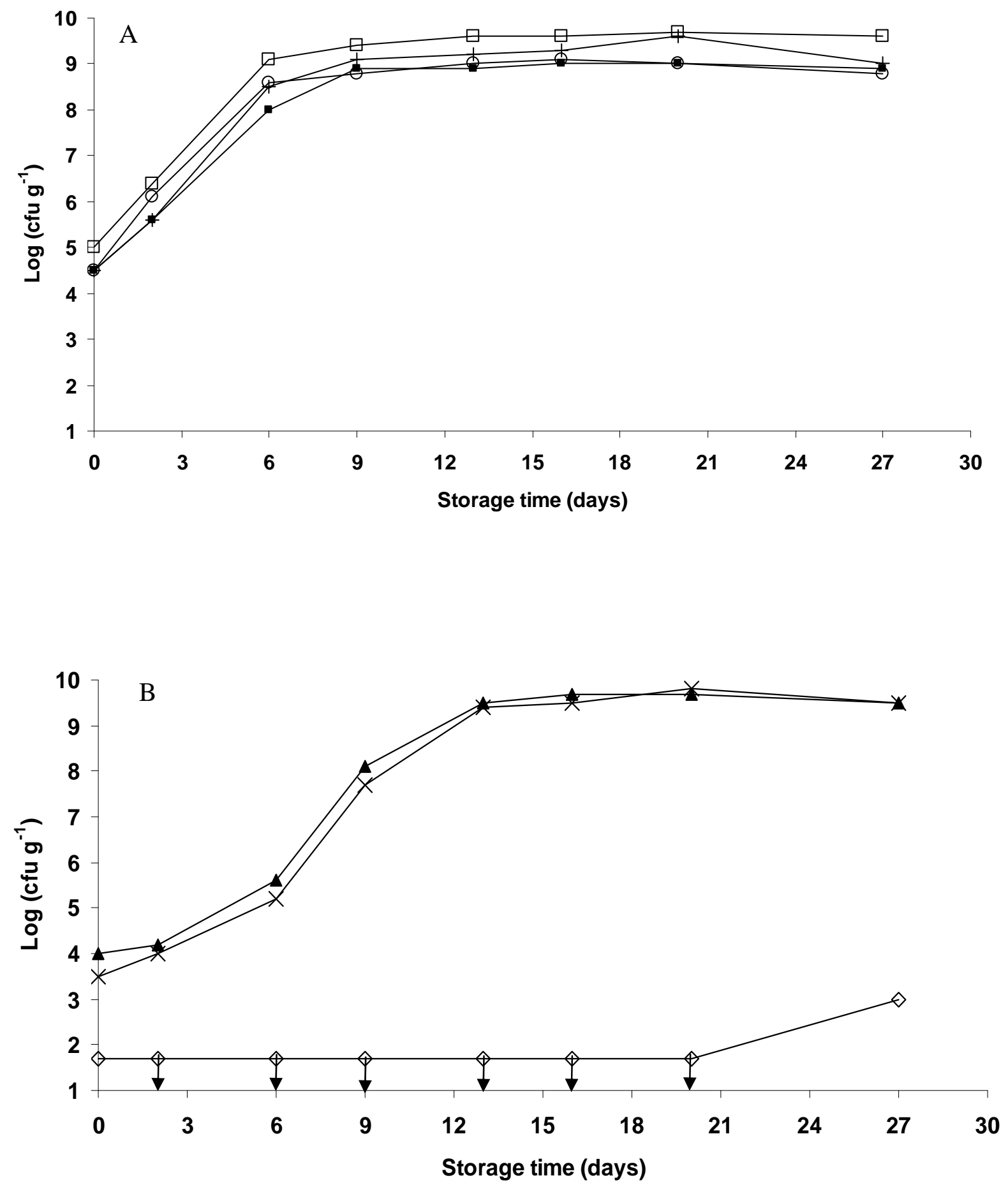
Fig. 2. Total volatile basic nitrogen (TVBN) production (mg-N $100 \mathrm{~g}^{-1}$ ) of bacterial groups inoculated on chilled and MAP cooked peeled tropical shrimps during storage at $8^{\circ} \mathrm{C}$. A: (口): Carnobacterium divergens, (+): Carnobacterium alterfunditum-like, (O): Serratia liquefacienslike, (घ): Brochothrix thermosphacta. B: (A): Carnobacterium maltaromaticum, $(\times)$ : Vagococcus penaei sp. nov., ( () : Control.
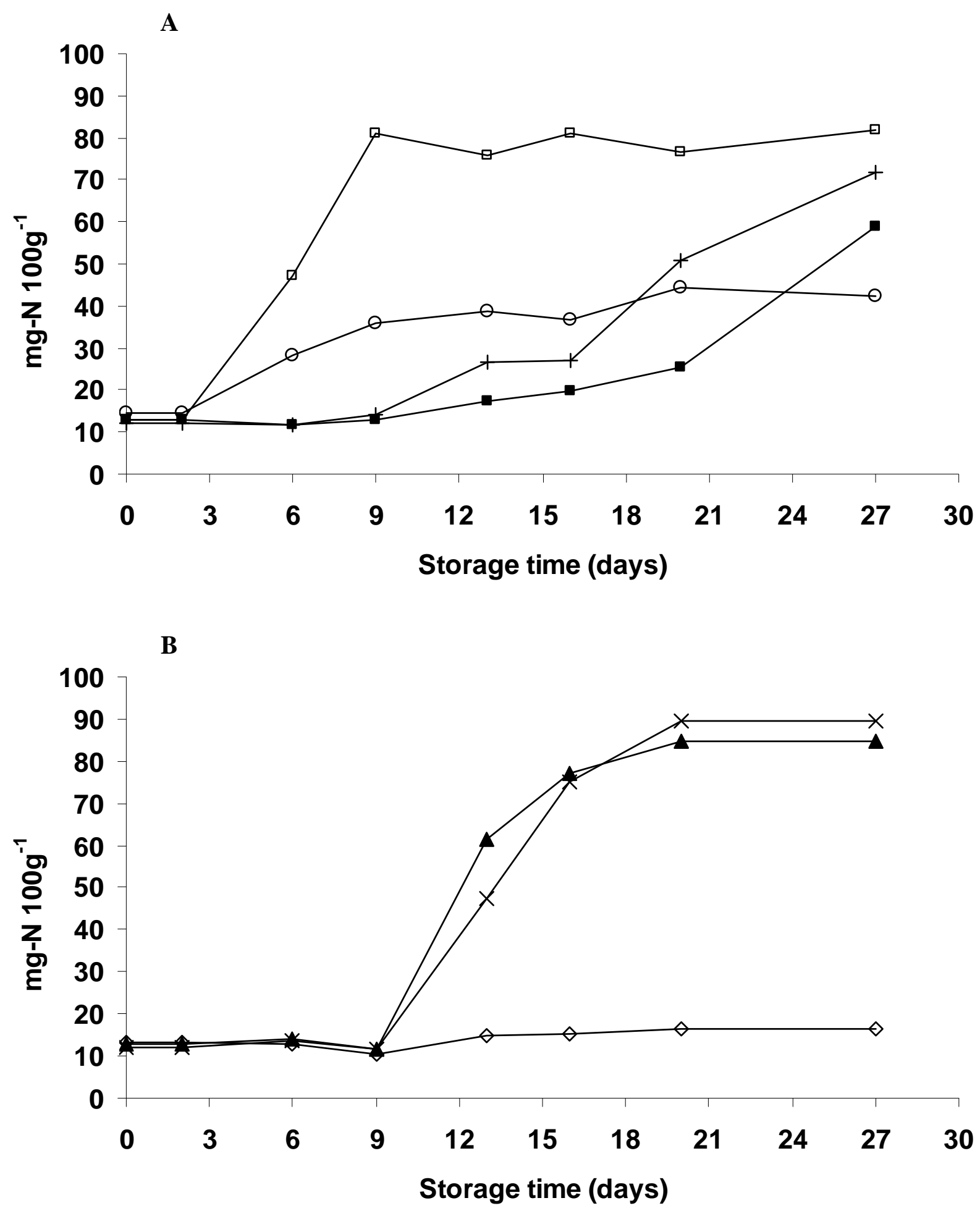
Fig. 3. Simultaneous representation of samples and spoilage levels of inoculated MAP shrimp samples stored at $8^{\circ} \mathrm{C}$ on plane 1-2 of a correspondence factorial analysis (CFA). NS: non-spoiled; LS: lightly spoiled; MS: moderately spoiled; SS: strongly spoiled. Sample nomenclature: C, control samples (non-inoculated); Bro, Brochothrix thermosphacta; SI, Serratia liquefaciens-like; $\mathrm{Cm}$, Carnobacterium maltaromaticum; Cd, Carnobacterium divergens; Ca, Carnobacterium alterfunditum-like; Vp, Vagococcus penaei. Numbers in labels of samples express duration of storage (in days).

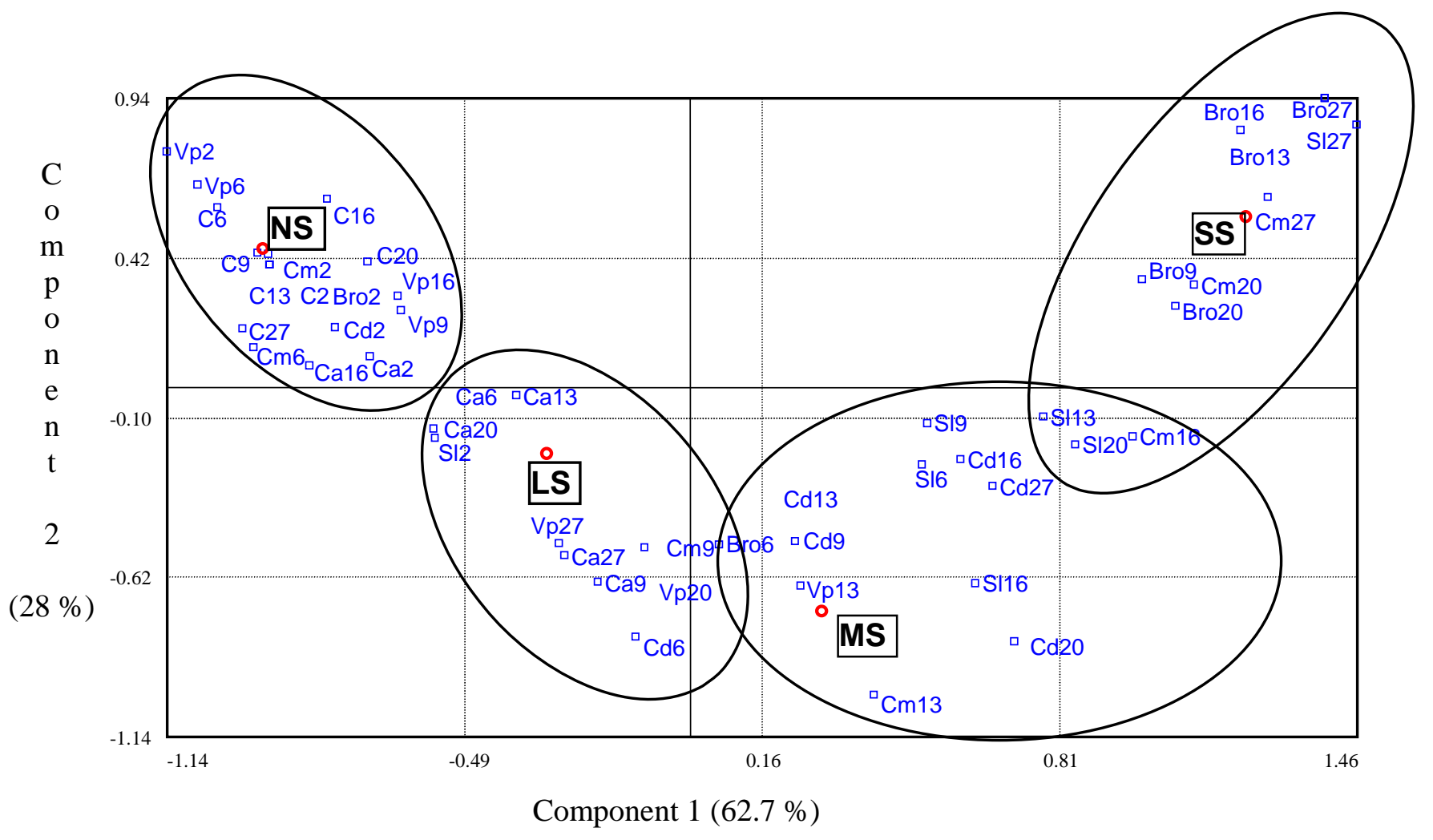


Fig. 4. Simultaneous representation of inoculated shrimp samples and odor descriptors on plane 1-2 of a principal component analysis. Sample nomenclature: C, control samples (noninoculated); Bro, Brochothrix thermosphacta; SI, Serratia liquefaciens-like; $\mathrm{Cm}$, Carnobacterium maltaromaticum; Cd, Carnobacterium divergens; Ca, Carnobacterium alterfunditum-like; Vp, Vagococcus penaei. Numbers in labels of samples express duration of storage (in days) and labels for sensory descriptors are defined in Table 2.

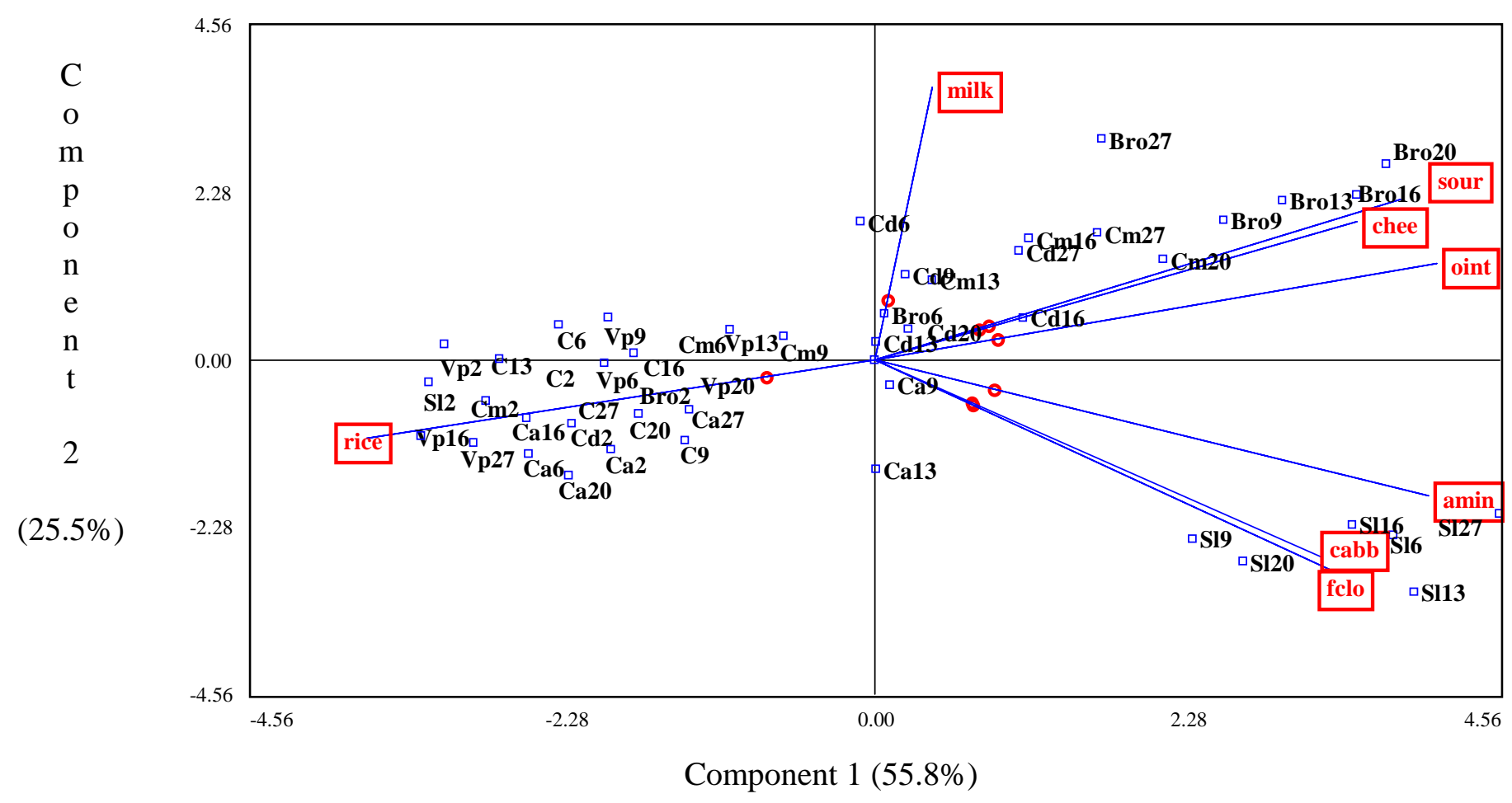


Table 1. Bacterial groups (reference numbers in IFREMER collection) inoculated on cooked and peeled tropical shrimps, by mixing strain cultures.

Bacterial species

Inoculated strain mixture $^{\mathrm{a}}$

Label of

mixture

Brochothrix thermosphacta

CD 251, CD 290, CD 340, CD 266, CD 274

Bro

Serratia liquefaciens-like

CD 249, CD 297, CD 298, CD 301, CD 302

Sl

Carnobacterium maltaromaticum

CD 253, CD 256, CD 257, CD 263, CD 300

$\mathrm{Cm}$

Carnobacterium divergens

CD 362, CD 314, CD 379, CD 320, CD 361

Cd

Carnobacterium alterfunditum-like

CD 332, CD 344, CD 345, CD 347, CD 348

$\mathrm{Ca}$

Vagococcus penaei sp. nov.

CD 276, CD 279, CD 285, CD 310, CD 380

$\mathrm{Vp}$

a CD: strain code in the bacterial collection of Institut français de recherche pour l'exploitation de la mer (IFREMER); CD for « crevette décortiquée », french designation of peeled shrimp.

Table 2. List of sensory spoilage descriptors selected for the shrimp sample analysis and corresponding label used in Fig. 4.

\begin{tabular}{cc}
\hline Descriptor of odor & Label \\
\hline Overall intensity of odor & oint \\
Rice/crustacean & rice \\
Milky/boiled & milk \\
Floor cloth & fclo \\
Sour/fermented & sour \\
Amine/urine & amin \\
Cheese/feet & chee \\
Cabbage/gas/garlic & cabb \\
\hline
\end{tabular}


Table 3. Conditions and odours assigned by an 11-member panel to samples of cooked shrimps inoculated with bacterial groups during 27 days of storage at $8^{\circ} \mathrm{C}$. Bacterial groups are classified in a decreasing order of spoilage potential.

\begin{tabular}{lcc}
\hline Bacterial group & Condition & Sensory characteristics \\
\hline Brochothrix thermosphacta & Spoiled & cheese/feet and sour/fermented \\
Serratia liquefaciens-like & Spoiled & cabbage/gas/garlic and amine/urine \\
Carnobacterium maltaromaticum & Spoiled & cheese/feet, sour/fermented and butter \\
Carnobacterium divergens & Weakly spoiled & sour/fermented and cheese/feet \\
Carnobacterium alterfunditum-like & Non-spoiled & rice/crustacean \\
Vagococcus penaei sp. nov. & Non-spoiled & rice/crustacean and butter (days 13, 16) \\
\hline
\end{tabular}

Table 4. Volatile compounds identified in inoculated, cooked and peeled tropical shrimps in MAP, after inoculation with bacterial strain groups and storage at $8^{\circ} \mathrm{C}^{a}$

\begin{tabular}{|c|c|c|c|c|}
\hline Volatile compound & $\begin{array}{l}\text { Non-inoculated } \\
\text { (control) }\end{array}$ & $\begin{array}{c}B . \\
\text { thermosphacta }\end{array}$ & $\begin{array}{c}S . \\
\text { liquefaciens }\end{array}$ & $\begin{array}{c}C . \\
\text { maltaromaticum }\end{array}$ \\
\hline \multicolumn{5}{|l|}{ Alcohols } \\
\hline 2-methyl-1-butanol & $<5.0$ & $6.7 \pm 0.04$ & $5.5 \pm 0.06$ & $6.6 \pm 0.03$ \\
\hline 3-methyl-1-butanol & $<5.0$ & $5.2 \pm 0.14$ & $<5.0$ & $5.0 \pm 0.03$ \\
\hline 1-propanol & $<5.0$ & $5.5 \pm 0.07$ & $6.4 \pm 0.15$ & $<5.0$ \\
\hline 1-penten-3-ol & $5.9 \pm 0.03$ & $<5.0$ & $5.0 \pm 0.13$ & $5.8 \pm 0.07$ \\
\hline cis-2-penten-1-ol & $5.1 \pm 0.12$ & $<5.0$ & $<5.0$ & $<5.0$ \\
\hline 2-methyl-1-propanol & $<5.0$ & $6.3 \pm 0.12$ & $<5.0$ & $<5.0$ \\
\hline 2-hexanol & $<5.0$ & $5.8 \pm 0.04$ & $<5.0$ & $<5.0$ \\
\hline 2-butanol & $<5.0$ & $<5.0$ & $6.0 \pm 0.3$ & $<5.0$ \\
\hline Cyclopentanol & $<5.0$ & $<5.0$ & $<5.0$ & $5.8 \pm 0.01$ \\
\hline \multicolumn{5}{|l|}{ Aldehydes } \\
\hline Acetaldehyde & $<5.0$ & $6.3 \pm 0.02$ & $6.4 \pm 0.02$ & $6.2 \pm 0.02$ \\
\hline 3-methyl-1-butanal & $<5.0$ & $7.4 \pm 0.06$ & $<5.0$ & $7.5 \pm 0.01$ \\
\hline 2-methyl-1-butanal & $<5.0$ & $6.9 \pm 0.18$ & $<5.0$ & $7.0 \pm 0.04$ \\
\hline pentanal & $<5.0$ & $5.6 \pm 0.53$ & $5.2 \pm 0.22$ & $<5.0$ \\
\hline 2-methyl-1-propanal & $<5.0$ & $6.3 \pm 0.13$ & $<5.0$ & $6.3 \pm 0.06$ \\
\hline \multicolumn{5}{|l|}{ Ketones } \\
\hline 2.3-butanedione & $<5.0$ & $7.1 \pm 0.07$ & $6.8 \pm 0.06$ & $6.2 \pm 0.18$ \\
\hline 2-propanone & $6.0 \pm 0.04$ & $6.0 \pm 0.04$ & $6.1 \pm 0.03$ & $6.1 \pm 0.02$ \\
\hline 3-pentanone & $5.2 \pm 0.12$ & $<5.0$ & $<5.0$ & $5.2 \pm 0.27$ \\
\hline 3-methyl-2-butanone & $<5.0$ & $<5.0$ & $<5.0$ & $6.5 \pm 0.07$ \\
\hline 2.3-heptanedione & $<5.0$ & $5.8 \pm 0.09$ & $<5.0$ & $<5.0$ \\
\hline \multicolumn{5}{|l|}{ Hydrocarbons } \\
\hline Methylbenzene & $5.1 \pm 0.18$ & $<5.0$ & $<5.0$ & $<5.0$ \\
\hline 2-pentene & $6.3 \pm 0.04$ & $6.0 \pm 0.05$ & $<5.0$ & $6.1 \pm 0.08$ \\
\hline 3-methyl-1-butene & $<5.0$ & $<5.0$ & $<5.0$ & $6.5 \pm 0.02$ \\
\hline \multicolumn{5}{|l|}{ Others } \\
\hline Methanethiol & $5.7 \pm 0.30$ & $6.0 \pm 0.01$ & $6.0 \pm 0.03$ & $6.1 \pm 0.04$ \\
\hline Ethyl acetate & $<5.0$ & $6.3 \pm 0.07$ & $6.8 \pm 0.08$ & $6.4 \pm 0.06$ \\
\hline Chloroform & $5.4 \pm 0.11$ & $<5.0$ & $<5.0$ & $<5.0$ \\
\hline Trimethylamine & $<5.0$ & $<5.0$ & $6.1 \pm 0.1$ & $<5.0$ \\
\hline Thiocarbamide (thiourea) & $<5.0$ & $<5.0$ & $<5.0$ & $6.1 \pm 0.15$ \\
\hline
\end{tabular}

${ }^{\mathrm{a}}$ Values are averages \pm standard deviation of $\log ($ peak area/g). $n=3$ 